\title{
Two new species of Cylicospirura Vevers, 1922 (Nematoda: Spirocercidae) from carnivores in southern Africa, with validation of the related genera Gastronodus Singh, 1934 and Skrjabinocercina Matschulsky, 1952
}

\author{
Kerstin Junker ${ }^{1}$, Emily P. Lane $^{2}$, Anna E. McRee ${ }^{3}$, Chris Foggin $^{4}$, D. Schalk van Dyk ${ }^{5}$ and Yasen Mutafchiev ${ }^{6}$ \\ ${ }^{1}$ ARC-Onderstepoort Veterinary Institute, Parasites, Vectors and Vector-borne Diseases Programme, Onderstepoort, South Africa; \\ ${ }^{2}$ National Zoological Gardens of South Africa, Research and Scientific Services, Pretoria, South Africa; \\ ${ }^{3}$ The University of Tennessee, College of Veterinary Medicine, Knoxville, TN, USA; \\ ${ }^{4}$ Wildlife Horizons, Wildlife Trust, Victoria Falls, Zimbabwe; \\ ${ }^{5}$ State Veterinary Services, Kruger National Park, Skukuza, South Africa; \\ ${ }^{6}$ Department of Animal Diversity and Resources, Institute of Biodiversity and Ecosystem Research, Bulgarian Academy of \\ Sciences, Sofia, Bulgaria
}

\begin{abstract}
Two new species of Cylicospirura Vevers, 1922 are described from carnivores from southern Africa. Cylicospirura crocutae Junker et Mutafchiev sp. n. from Crocuta crocuta (Erxleben) in Zimbabwe is distinguished from its congeners by combinations of characters, including the presence of four cephalic and four external labial papillae, while internal labial papillae were not distinct, the presence of groups of small accessory teeth between the six large tricuspid teeth, the fifth and the sixth pairs of the caudal papillae being equidistant from the cloaca, and a large ratio of length of the muscular oesophagus to that of the glandular oesophagus. Cylicospirura pardalis Junker et Mutafchiev sp. n. from Panthera pardus (Linnaeus) in the Republic of South Africa is characterized by having tricuspid teeth with large, claw-like, abaxial cusps, four cephalic and six internal labial papillae. Based on the number of caudal papillae and the position of the vulva, the subgenera Gastronodus Singh, 1934 and Skrjabinocercina Matschulsky, 1952 are re-elevated to generic rank. Amended diagnoses are proposed for the genera Cylicospirura, Gastronodus and Skrjabinocercina. Petrowospirura lyncis Matschulsky, 1952 is recognized as valid and, together with P. petrowi Sadykhov, 1957 and P. barusi Arya, 1979, is transferred to Cylicospirura as C. lyncis (Matschulsky, 1952) Junker et Mutafchiev comb. n., C. petrowi (Sadykhov, 1957) Junker et Mutafchiev comb. n. and C. barusi (Arya, 1979) Junker et Mutafchiev comb. n., respectively.
\end{abstract}

Keywords: Petrowospirura, Crocuta crocuta, Panthera pardus, carnivores, taxonomy, Africa

The genus Cylicospirura Vevers, 1922 was erected as monotypic for C. subaequalis (Molin, 1860) Vevers, 1922 (syn. Spiroptera subaequalis Molin, 1860) from Puma concolor (Linnaeus) and Puma yagouaroundi (Geoffroy) (Carnivora: Felidae) in Brazil (Molin 1860, Vevers 1922). The genus went largely unnoticed until Chabaud (1959a,b) examined the cephalic structures of a collection of spirurids from carnivores. Based on the presence of a mouth without median lobes and a buccal capsule armed with six teeth, being simple or with two or three cusps, several species were assigned to Cylicospirura: C. arctica (Petrow, 1927) Chabaud, 1959 (syn. Spirocerca arctica Petrow, 1927), C. heydoni (Baylis, 1927) Chabaud, 1959 (syn. Spirocerca heydoni Baylis, 1927), C. petrowi (Matschulsky, 1952) Chabaud, 1959 (syn. Skrjabinocercina petrowi Matschulsky, 1952) and C. strasseni (Singh, 1934) Chabaud, 1959 (syn. Gastronodus strasseni Singh,
1934) (see Chabaud 1959b). In addition, Chabaud (1959b) recognized Petrowospirura lyncis Matschulsky, 1952 as a synonym of the type species $C$. subaequalis.

In a subsequent publication, Chabaud (1975) considered three subgenera within the genus Cylicospirura: the nominotypical subgenus harbouring parasites of carnivores and dasyurid marsupials; the monotypic Gastronodus Singh, 1934 from shrews (originally spelled out as 'Castronodus' but subsequently corrected, see Singh 1948) and Skrjabinocercina Matschulsky, 1952 from rodents. To date, six species, predominantly from felid and canid carnivores and dasyurid marsupials, have been recognized within the nominotypical subgenus worldwide (see below). A single species, C. subaequalis, has been recorded from large African carnivores (Sandground 1929, Round 1968, Graber and Thal 1980, Graber et al. 1980). The scarcity of data on Cylicospirura in these carnivores, 
especially in recent years, most likely reflects the nature of their hosts and does not necessarily indicate a low prevalence of these parasites. According to the International Union for Conservation of Nature, the conservation status of the spotted hyaena, Crocuta crocuta (Erxleben), is still listed as of least concern, but with population numbers that continue to decline outside protected areas due to habitat loss, persecution and hunting for trade and pest control (Honer et al. 2008). In contrast, that of the leopard, Panthera pardus (Linnaeus), is near threatened (Henschel et al. 2008), and lions, Panthera leo (Linnaeus), are listed as vulnerable (Bauer et al. 2008). Thus, opportunities to study their helminth fauna are rare.

Recently, material from two carnivores from southern Africa, collected during post mortem examinations, has become available. While easily identified as belonging to Cylicospirura, the specimens differed from the known species. They are described below as two new species, one from a spotted hyaena in Zimbabwe and one from a leopard in the Republic of South Africa. In addition, the morphological characteristics of all species described as belonging to Cylicospirura, Gastronodus, Petrowospirura Matschulsky, 1952 or Skrjabinocercina have been critically assessed and their taxonomic status evaluated. As a result, Gastronodus and Skrjabinocercina are proposed here as valid genera (and not as subgenera of Cylicospirura). Their generic diagnoses, together with that of Cylicospirura, are amended. Cylicospirura lyncis (Matschulsky, 1952) comb. n. is validated and, along with C. petrowi (Sadykhov, 1957) comb. n. and C. barusi (Arya, 1979), comb. n., is transferred to the genus Cylicospirura.

\section{MATERIALS AND METHODS}

Helminths were fixed and stored in $70 \%$ ethanol and cleared in lactophenol for morphological studies. Apical views were cut using a razor blade. Specimens were studied under a compound microscope (Olympus BX51) equipped with a drawing tube and digital camera (Olympus DP72). Photos and measurements were taken with the aid of digital imaging software (Olympus cellSens Dimension, version 1.4.1). All measurements are given in micrometres unless otherwise indicated. The tail papillae are numbered according to Chabaud and Petter (1961). Because these nematodes are tightly embedded in the nodular tissue, it is not always possible to extract entire nematodes and some of the material is fragmented. All specimens were deposited in the National Collection of Animal Helminths, ARC-Onderstepoort Veterinary Institute, South Africa (NCAH). Mammalian nomenclature follows Wilson and Reeder (2005).

\section{RESULTS}

Cylicospirura crocutae Junker et Mutafchiev sp. n.

Figs. 1, 2

Description. Medium-sized worms. Body cylindrical, tapering at both ends; maximum body width at oesophago-intestinal junction. Cuticle with narrow transverse stri- ations, spaced approximately $3 \mu \mathrm{m}$ apart. Mouth opening hexagonal, delineated by six sclerotized, lip-like crescents in the lateral and submedian positions (Fig. 1B). Buccal capsule large, heavily sclerotized, goblet-shaped, with cylindrical base (Figs. 1C,D, 2B,E). Six large teeth arise in posterior half of buccal capsule, projecting anteriorly. Each tooth bearing three cusps; lateral cusps rounded and knob-like, central cusp slightly elongated. Between large teeth, six groups of four to six small accessory teeth arise from buccal capsule wall, projecting into it (Figs. 1B, 2A). Amphids aligned with two lateral large teeth. Eight head papillae, comprising four cephalic papillae and four external labial papillae, arranged in two almost overlapping circles at level of amphids and aligned with base of submedian large teeth (Figs. 1B, 2A). Internal labial papillae not seen. Oesophagus divided into anterior muscular and posterior glandular part (Figs. 1A,D, 2C); muscular oesophagus nearly cylindrical, glandular oesophagus subtly increasing in width posteriorly, with widest part at oesophago-intestinal junction. Deirids small, spine-like, at level of nerve ring or slightly anterior or posterior to it; excretory pore slightly posterior to nerve ring; nerve ring, deirids and excretory pore at level of muscular oesophagus (Fig. 1C,D).

Male (based on holotype; measurements of a single posterior fragment in parentheses when available; see Table 1 for additional measurements). Buccal capsule 139 long, including cylindrical base 57 long (Figs. 1D, 2E). Deirids at 466 and 487 from anterior end, excretory pore at 570 from anterior end. Muscular and glandular oesophagus 106 and 247 wide, respectively; ratio of muscular to glandular oesophagus length $1: 9.1$; total oesophagus length $26.3 \%$ of body length. Testis extending to level slightly posterior to oesophago-intestinal junction. Tail coiled ventrally, $1.5 \%$ of body length. Caudal alae narrow, $1.26 \mathrm{~mm}$ long in posterior fragment in ventral view (Fig. 1E, 2F). Area rugosa consisting of distinct, parallel, longitudinal cuticular ridges; absent in area around cloaca and subterminal papillae; extending 2.7 (2.3) mm anteriorly from tip of tail. Cloaca slit-like, without conspicuous cuticular lips.

Ten pairs of caudal papillae; pairs 1-4 ventrolateral, precloacal, pedunculate, not equidistant from each other, distance between pairs 2 and 3 larger than between 1 and 2 , and 3 and 4, respectively; pairs 3 and 4 slightly smaller than pairs 1 and 2; pairs 5 and 6 postcloacal, pedunculate, at same distance from cloaca, pair 5 ventral, slightly smaller than ventrolateral pair 6; pairs 7-10 small, sessile, arranged in subterminal group around cuticular pads near tip of tail; phasmids situated between pairs 9 and 10 . A single, large, sessile, median papilla anterior to cloaca. Spicules unequal and dissimilar; left spicule long and slender, tapering to pointed tip; right spicule short, robust with round tip (Fig. 1F,G); spicular ratio $1: 4.0$ (1: 4.1). Gubernaculum present, irregularly shaped, 144 long (Fig. 1H). 


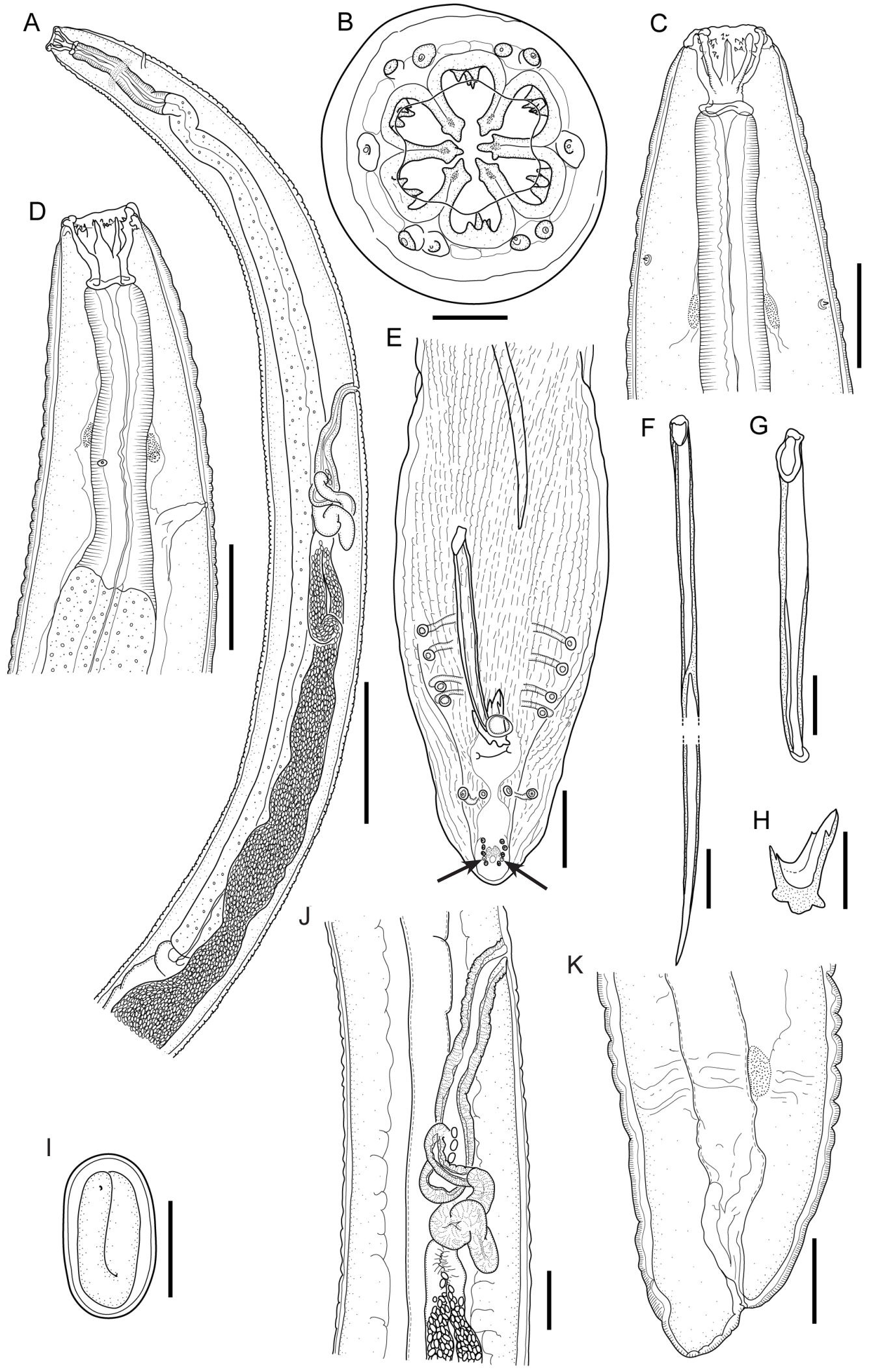

Fig. 1. Cylicospirura crocutae sp. n. from Crocuta crocuta. A - anterior end, female, lateral view; B - head, female, apical view; $\mathbf{C}$ - anterior end, female, ventral view; D - anterior end, male, lateral view; $\mathbf{E}$ - posterior end, male, ventral view, note phasmids (black arrows); F - proximal and distal end of left spicule, subventral view; $\mathbf{G}$ - right spicule, subventral view; $\mathbf{H}$ - gubernaculum, subventral view; I - egg; $\mathbf{J}$ - vagina, ovejector and beginning of uterus, female, lateral view; $\mathbf{K}$ - posterior end, female, lateral view. Scale bars in micrometres: $A=1000 ; B=50 ; C-E, J=200 ; F-H, K=100 ; I=25$. 


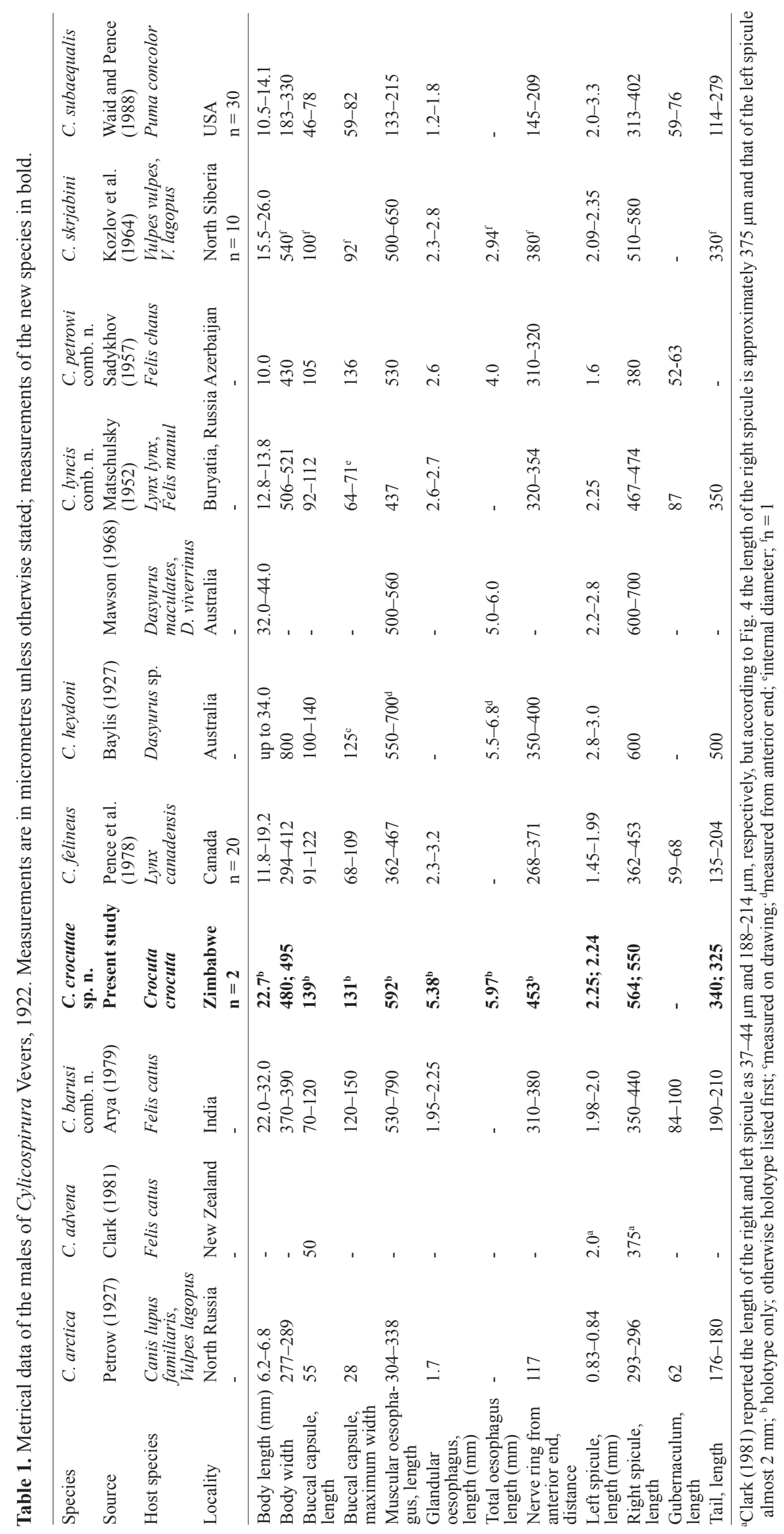



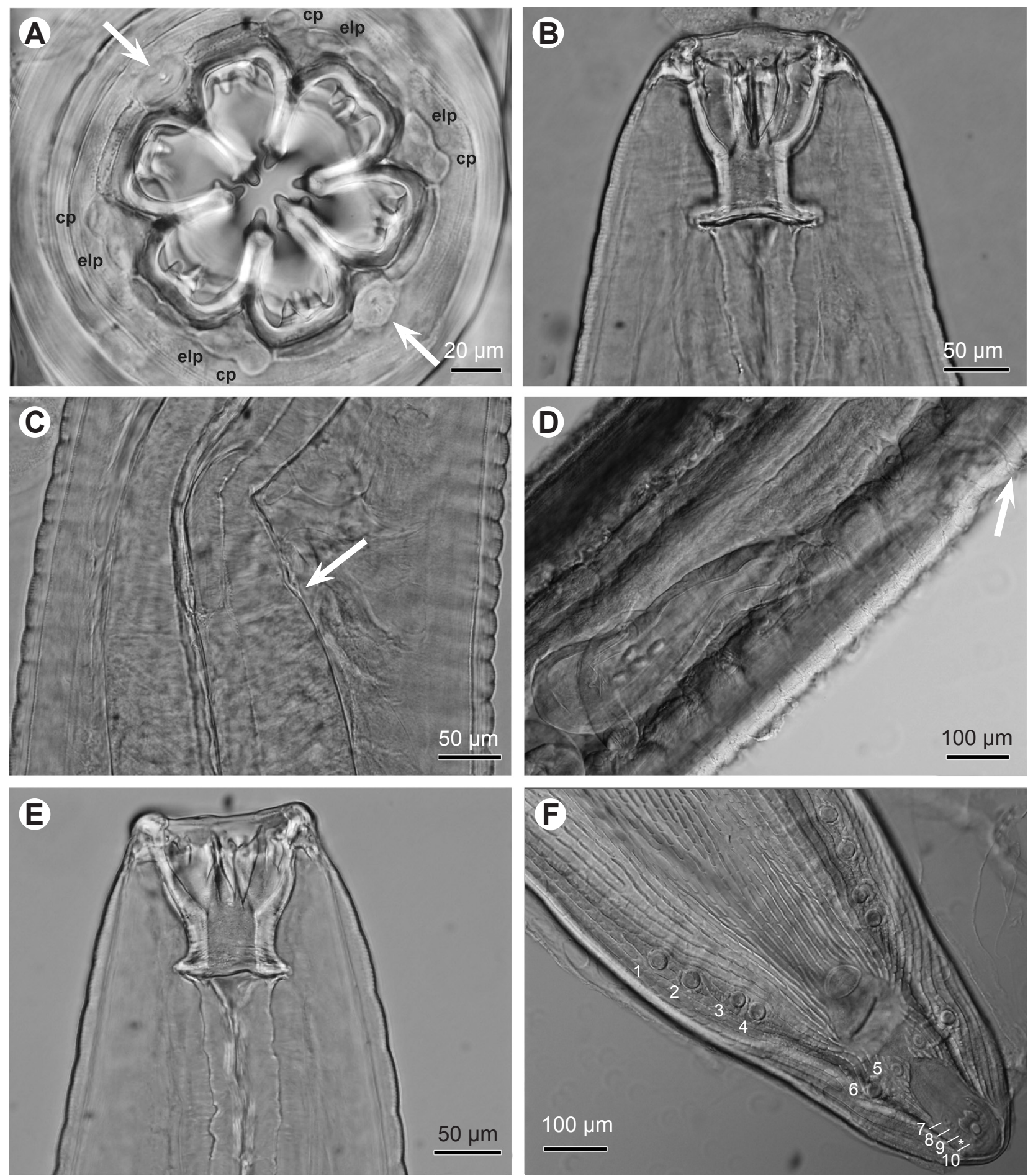

Fig. 2. Cylicospirura crocutae sp. n. from Crocuta crocuta. A-D female; A - head, apical view; cp - cephalic papilla; elp - external labial papilla; arrows indicating amphids; $\mathbf{B}$ - anterior end, ventral view; $\mathbf{C}$-junction of muscular and glandular oesophagus (arrow), lateral view; D - vagina and ovejector, lateral view, arrow indicating vulva; E, F male; $\mathbf{E}$ - anterior end, lateral view; $\mathbf{F}$ - posterior end with caudal papillae, papillae on right numbered according to Chabaud and Petter (1961), asterisk indicating phasmid.

Female (based on two anterior fragments; measurements of second specimen in parentheses, followed by those of a third when available; see Table 2 for additional measurements). Buccal capsule 162 (175) long, including cylindrical base 62 (64) long. Deirids at 433 and 525
(477 and 529) from anterior end; excretory pore at 642 (626) from anterior end. Muscular oesophagus 821 (814) long, 117 (119) wide; glandular oesophagus 6.03 (6.58; 6.29) $\mathrm{mm}$ long, maximum width $285(273 ; 275)$; ratio of muscular to glandular oesophagus $1: 7.3(1: 8.1 ; 1: 8.5)$. 


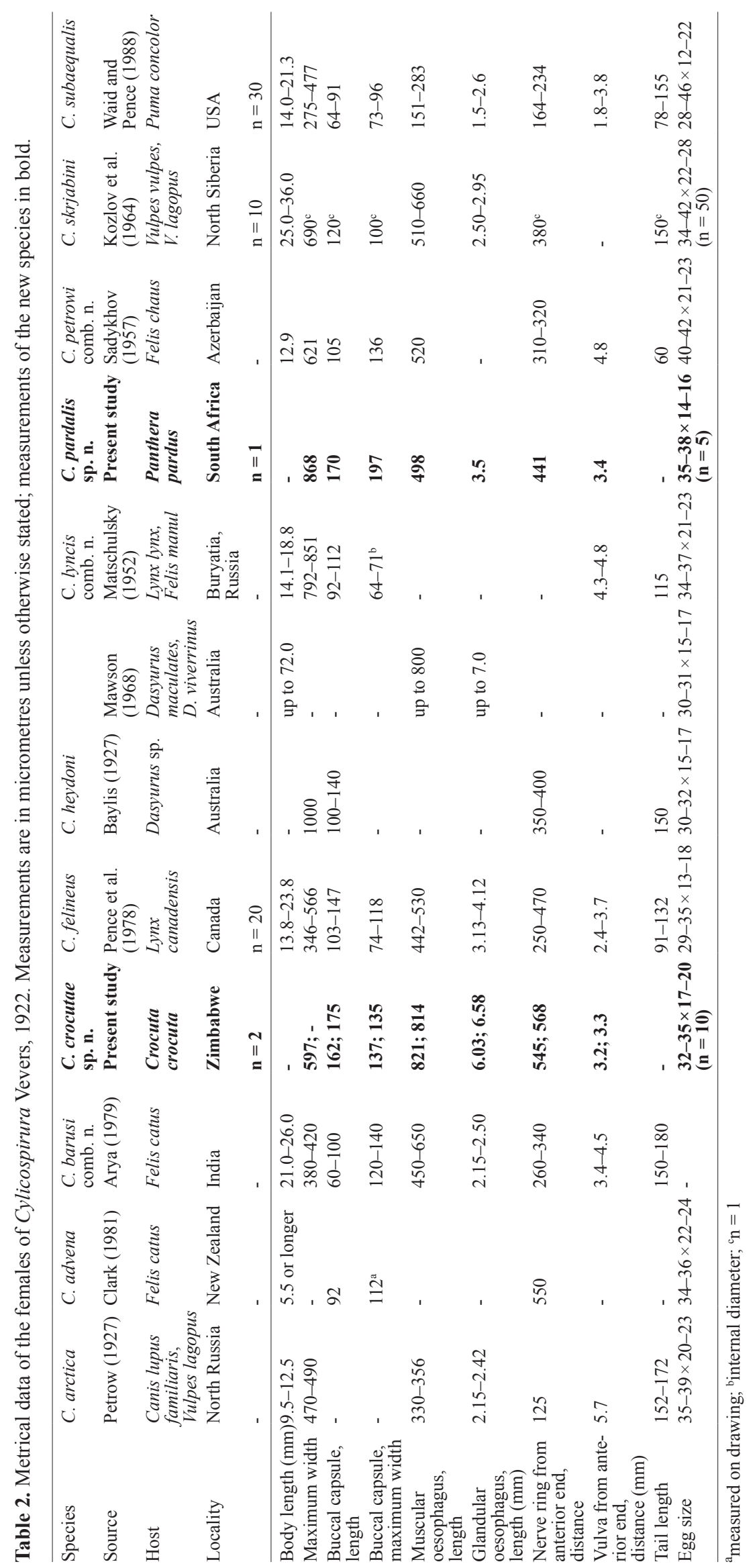


Genital tract didelphic, opisthodelphic. Vulva without salient lips, opening anterior to oesophago-intestinal junction (Fig. 1A). Vagina simple, pouch-like, directed posteriorly (a forward loop in second specimen likely an artefact of specimen damage), 821 (902) long, joined in posterior third by muscular and convoluted ovejector (Figs. 1J, 2D). Eggs thick-shelled, with well-developed first-stage larva (Fig. 1I). In two posterior fragments, tail 93 and 116 long, respectively, broadly conical (Fig. 1K).

Type host: Crocuta crocuta (Erxleben) (Carnivora: Hyaenidae); collected on 26 June 2012.

Type locality: Victoria Falls Private Game Reserve (Nakavango Estates; $18^{\circ} 00^{\prime} 48^{\prime \prime S} ; 25^{\circ} 46^{\prime} 42^{\prime \prime E}$ ), Victoria Falls, Zimbabwe.

Site: Nodules in stomach.

Type specimens: Holotype: NCAH.2.1 (male). Paratypes: NCAH.2.2 (posterior fragment of male); NCAH.2.3-4 (two anterior fragments of females); NCAH.2.5 (anterior fragment of female, used for apical view of head); NCAH.2.6-7 (two posterior fragments of females).

Etymology: This species is named after its host.

Remarks. Cylicospirura crocutae sp. n. conforms to the generic diagnosis of Cylicospirura by having six large teeth that arise from the posterior half of the buccal capsule, four pairs of pedunculate precloacal papillae and a vulva positioned near the oesophago-intestinal junction (see below). However, C. crocutae can be readily distinguished from all its congeners (except probably C. barusi, see below) by the presence of groups of small accessory teeth between the six main teeth that are absent in the remaining species; in addition, males of the new species are characterized by the position of the fifth pair of caudal papillae, situated between the two papillae of the sixth pair (both pairs are equidistant from the cloaca), which contrasts with the more posteriorly positioned sixth pair in the remaining species (Baylis 1927, Petrow 1927, Matschulsky 1952, Sadykhov 1957, Kozlov et al. 1964, Mawson 1968, Pence et al. 1978, Arya 1979, Clark 1981, Waid and Pence 1988).

By having four pairs of submedian papillae that surround the mouth opening, $C$. crocutae resembles $C$. barusi, which, however, differs by having simple large teeth without cusps, the lateral ones of which are shorter than the submedian ones, and a shorter right spicule (350-440 $\mu \mathrm{m}$ vs $550 \mu \mathrm{m}$ and $564 \mu \mathrm{m})$. Whereas males of $C$. barusi are similar or larger in size, the length of the glandular oesophagus is barely half that in C. crocutae (Table 1).

The number and arrangement of the head papillae distinguish the new species from the majority of the congeners. Cylicospirura crocutae possesses four external labial and four cephalic papillae that are uniform in size and arranged in two almost overlapping circles at the level of the amphids, while internal labial papillae were not seen. In contrast, C. advena Clark, 1981, C. felineus (Chandler,
1925), C. skrjabini Kozlov, Owsjukova et Radkewitch, 1964 and C. subaequalis are characterized by four cephalic and six internal labial papillae (Kozlov et al. 1964, Pence et al. 1978, Clark 1981, Waid and Pence 1988); C. heydoni possesses four cephalic, four external labial and six internal labial papillae (Mawson 1968); for C. lyncis, six internal labial papillae are illustrated (Matschulsky 1952). No information is available for C. arctica and C. petrowi. A number of additional characters differentiate the present specimens from the latter two species (see below).

Of the nine species of Cylicospirura, only two possess teeth with three distinct cusps, C.felineus and C. skrjabini (see Kozlov et al. 1964, Pence et al. 1978). The cusps are of equal size and arranged in a row on the anterior border of each tooth, rounded in C.felineus and conical in C. skrjabini (see Kozlov et al. 1964, Pence et al. 1978, Junker et al. 2006); those of C. crocutae are rounded, with the median cusp being elongate and situated slightly anterior to the lateral two. The largest males of $C$. felineus are similar in size to the single entire male of C. crocutae $(19.2 \mathrm{~mm}$ vs $22.7 \mathrm{~mm}$ ) but their muscular and especially glandular oesophagus is distinctly shorter than that of the new species (362-467 $\mu \mathrm{m} v \mathrm{~s} 592 \mu \mathrm{m}$ and 2.3-3.2 mm vs $5.38 \mathrm{~mm}$, respectively). Similarly, in a single male of C. skrjabini, $21 \mathrm{~mm}$ long, the glandular oesophagus is only $2.3 \mathrm{~mm}$ long and the muscular to glandular oesophagus length ratio is $1: 3.6$ as opposed to $1: 9.1$ in the present male. The position of the vulva is at the oesophageal level in C. crocutae and C. felineus, but at the intestinal level in C. skrjabini.

In addition to the differences outlined above, C. lyncis can be distinguished from $C$. crocutae by having teeth with a variable number of indistinct cusps, ranging from smooth to tricuspid in the same specimen (Fig. 6 of Matschulsky 1952) and a shorter muscular to glandular oesophagus length ratio in males $(1: 6.1$ vs 1 : 9.1; Table 1).

Baylis (1927) described C. heydoni as having tricuspid teeth, illustrated as sharply pointed in lateral view and conical with less acute tips in apical view, with the central cusp being longer than the lateral ones. Mawson (1968), however, described and illustrated the teeth as having a single, sharply pointed cusp. Whereas males of C. heydoni reach almost twice the length of the male of C. crocutae (32-44 $\mathrm{mm}$ vs $22.7 \mathrm{~mm}$ ), their total oesophagus $(5.0-6.0 \mathrm{~mm})$ as well as their muscular oesophagus length $(500-560 \mu \mathrm{m})$ is close to that seen in C. crocutae (5.97 and $5.92 \mathrm{~mm}$, respectively; Table 1).

The teeth of $C$. subaequalis bear two cusps, thus giving their apex a spanner-like appearance in apical view. The buccal capsule of males and females is narrower $(59-82 \mu \mathrm{m}$ and 73-96 $\mu \mathrm{m})$ and shorter $(46-78 \mu \mathrm{m}$ and $64-91 \mu \mathrm{m})$ than that of $C$. crocutae $(131 \mu \mathrm{m}$ and 135-137 $\mu \mathrm{m}$ wide; $139 \mu \mathrm{m}$ and $162-175 \mu \mathrm{m}$ long). Based on the ranges provided by Waid and Pence (1988), the 

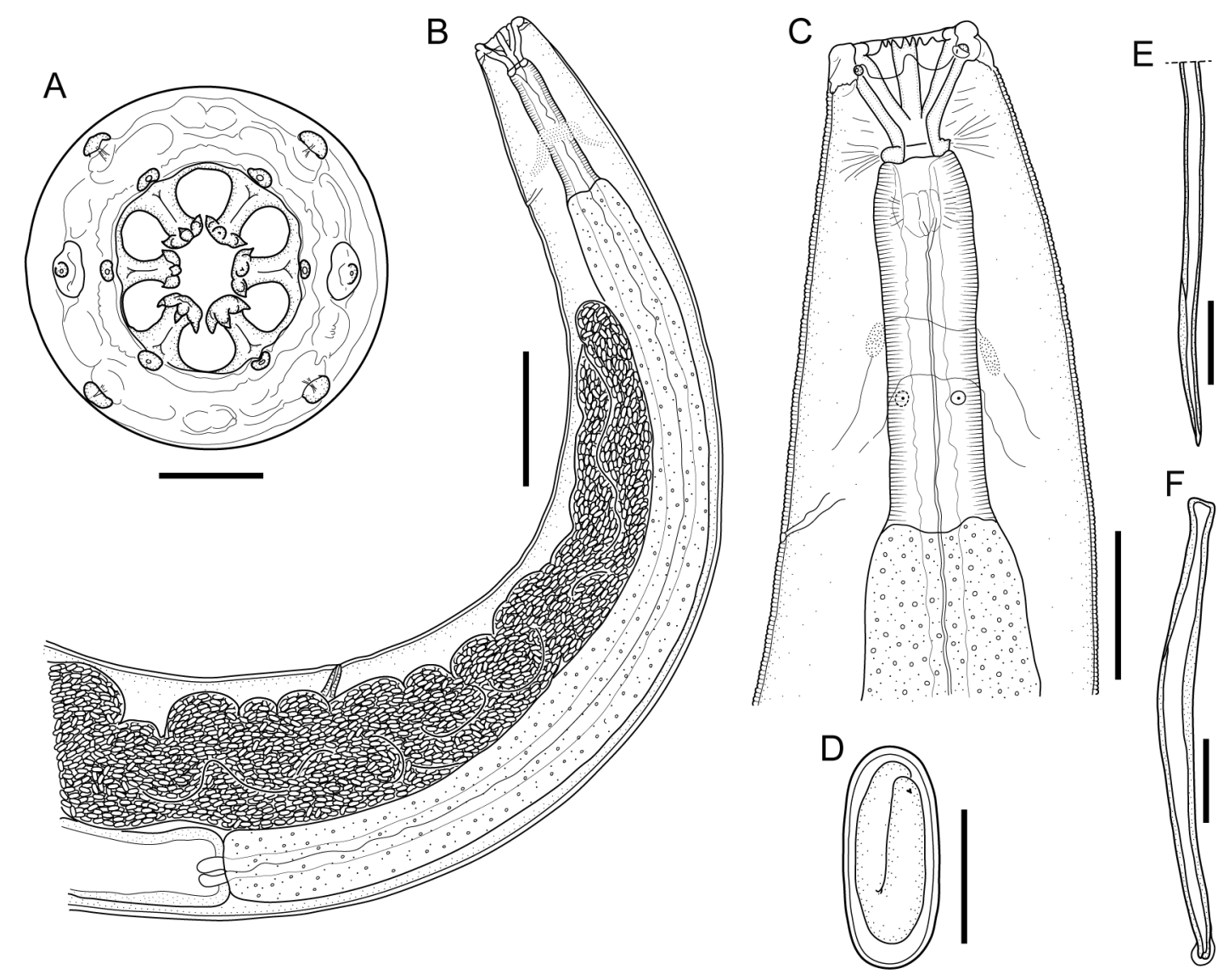

Fig. 3. Cylicospirura pardalis sp. n. from Panthera pardus. A - head, male, apical view; B, C female; B - anterior end, female, lateral view; $\mathbf{C}$ - anterior end, lateral view; $\mathbf{D}$ - egg; $\mathbf{E}$ - distal end of left spicule, subventral view; F - right spicule, subventral view. Scale bars in micrometres: $\mathrm{A}=50 ; \mathrm{B}=500 ; \mathrm{C}=200 ; \mathrm{D}=25 ; \mathrm{E}, \mathrm{F}=100$.

oesophagus reaches a maximum of $19.2 \%$ of the body length in C. subaequalis males compared to $26.3 \%$ in the male of $C$. crocutae. The position of the vulva is at the intestinal level in C. subaequalis, but at the oesophageal level in the present specimens.

Teeth that carry a single, sharply pointed cusp each and the smaller body size of the males $(6.2-6.8 \mathrm{~mm} v \mathrm{~s}$ $22.7 \mathrm{~mm}$ ) distinguish $C$. arctica from C. crocutae. Furthermore, the tip of the tail of $C$. arctica females is narrowly conical and the position of the vulva is intestinal (Petrow 1927).

Cylicospirura advena differs from C. crocutae by having smoothly rounded teeth without cusps and a shorter buccal capsule $(50 \mu \mathrm{m}$ in males and $92 \mu \mathrm{m}$ in females $v s$ $139 \mu \mathrm{m}$ and $162-175 \mu \mathrm{m}$, respectively; Tables 1, 2; Clark 1981). Cylicospirura petrowi males are half the size of the male of C. crocutae sp. n. and have a smaller muscular to glandular oesophagus ratio $(1: 4.9 v s$ 1:9.1; Table 1$)$.

Despite the low number of specimens at our disposal, the available diagnostic criteria, especially the configuration of the large teeth, as well as the presence of small accessory teeth, carry sufficient weight to unequivocally differentiate the current specimens from all remaining species of Cylicospirura.
Cylicospirura pardalis Junker et Mutafchiev sp. n.

Figs. 3, 4

Description. Body gradually tapering anteriorly, maximum body width at oesophago-intestinal junction. Cuticle with narrow transverse striations, spaced approximately $3 \mu \mathrm{m}$ apart. Lateral alae absent. Mouth opening hexagonal, delineated by six sclerotized, lip-like crescents in the lateral and submedian positions (Fig. 3A, 4A). Buccal capsule large, heavily sclerotized, funnelshaped, with cylindrical base representing one third of its length (Figs. 3C, 4B,C). Six large cuticular teeth arising in posterior half of buccal capsule, projecting anteriorly; each tooth bearing three large, abaxial, claw-like cusps (Figs. 3A, 4A). Groups of small teeth between large teeth absent. Close to mouth opening, six small internal labial papillae, in lateral and submedian positions; slightly posterior to level of amphids, four large cephalic papillae; amphids in line with two lateral teeth, cephalic papillae almost opposite of submedian teeth, not quite in line with internal labial papillae (Figs. 3A, 4A); external labial papillae not seen. Oesophagus divided into anterior muscular and posterior glandular part (Figs. 3B,C, 4C); muscular oesophagus nearly cylindrical; distinct increase in width between muscular and glandular oesophagus; glan- 

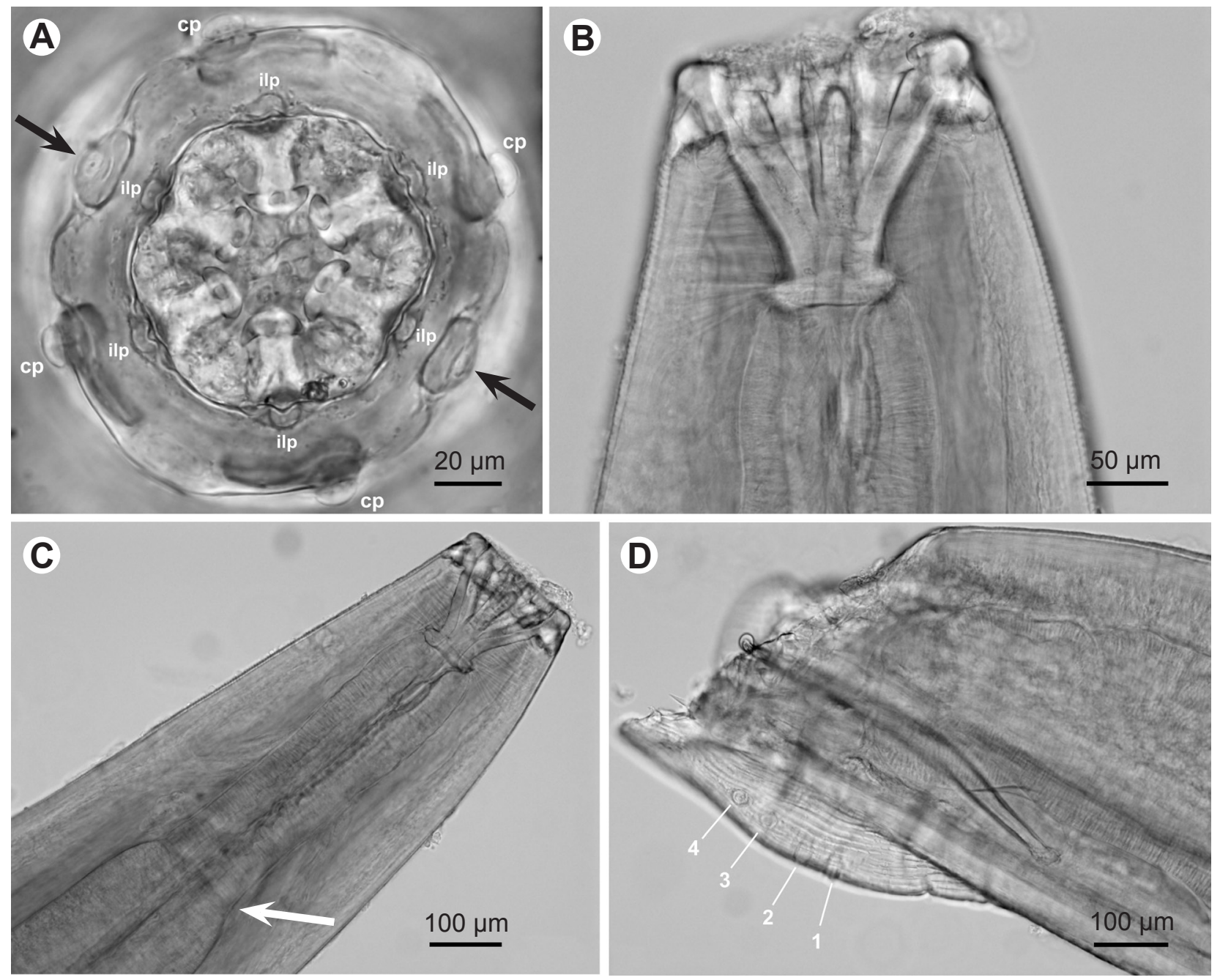

Fig. 4. Cylicospirura pardalis sp. n. from Panthera pardus. A - head, male, apical view; cp, cephalic papillae; ilp, internal labial papilla; arrows indicating amphids; B, C female; $\mathbf{B}$ - anterior end, lateral view; $\mathbf{C}$ - anterior end, including junction of muscular and glandular oesophagus (arrow); D - damaged posterior end of male, ventral view, illustrating the four precloacal papillae, numbered according to Chabaud and Petter (1961), and the right spicule.

dular oesophagus subtly increasing in width posteriorly, its widest part at oesophago-intestinal junction. Deirids small, spine-like, slightly posterior to nerve ring. Excretory pore posterior to deirids (Fig. 3C).

Male (based on one anterior and one posterior fragment with damaged tail tip). Length of anterior fragment $11 \mathrm{~mm}$. Maximum width 618. Width of muscular oesophagus 101. Length of glandular oesophagus $3.1 \mathrm{~mm}$, width 324. Pairs 1-4 of caudal papillae discernible, pedunculate, precloacal (Fig. 4D). Area rugosa consists of distinct, parallel, longitudinal cuticular ridges, extending $2.13 \mathrm{~mm}$ anteriorly, when measured from level of pair 4 of the caudal papillae. Spicules unequal and dissimilar; left spicule slender, its proximal part broken off, remaining fragment $2.71 \mathrm{~mm}$ long, tapering to pointed tip (Fig. 3E); right spicule 568 long, with round tip (Figs. 3F, 4D).

Female (based on one female anterior fragment; see Table 2 for additional measurements). Buccal capsule 170 long, including cylindrical base 58 long. Deirids and excretory pore at 491 and 643 from anterior end, respectively. Muscular and glandular oesophagus 143 and 274 wide, respectively; ratio of muscular to glandular oesophagus length 1 : 7.0. Genital tract didelphic, opisthodelphic. Vulva without salient lips, slightly anterior to oesophago-intestinal junction (Fig. 3B); vagina and ovejector muscular, partially obscured by eggs. Eggs thick-shelled, slightly elongated with almost parallel sides, containing well-developed first-stage larva (Fig. 3D).

Type host: Panthera pardus (Linnaeus) (Carnivora: Felidae); collected on 31 March 2011.

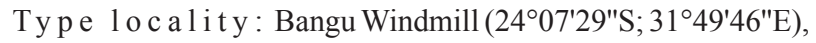
Kruger National Park, Mpumalanga Province, South Africa. Site: Nodules in oesophagus.

Type specimens: Holotype: NCAH.3.1 (anterior fragment of female). Paratypes: NCAH.3.2 (posterior fragment of male, tip of tail missing); NCAH.3.3 (anterior fragment 
of male, head cut for apical view); NCAH.3.4 (fragment of female, containing eggs).

Etymology: This species is named after its host.

Remarks. In having tricuspid teeth, C. pardalis sp. n. resembles C. skrjabini, C. felineus, C. crocutae sp. n. and C. lyncis (see above). It differs from them by the larger size of the cusps, their distinct claw-like appearance and abaxial orientation. The cusps are rounded in C. felineus and $C$. crocutae, conical with rounded tips in C. skrjabini, and indistinct and variable in number in C. lyncis; they all are directed adaxially (Matschulsky 1952, Kozlov et al. 1964, Pence et al. 1978). Cylicospirura skrjabini further differs from $C$. pardalis by a smaller muscular to glandular oesophagus length ratio in females $(1: 3.8-5.7 \mathrm{vs}$ $1: 7.0$ ) and the intestinal position of the vulva (Table 2). In $C$. crocutae, six groups of small teeth are arranged between the six large teeth, whereas accessory teeth are absent in the present specimens.

In C. heydoni, originally described with tricuspid teeth (Baylis 1927) and later as having teeth with a single, sharply pointed, conical cusp (Mawson 1968), the length of the muscular (up to $800 \mu \mathrm{m}$ ) and glandular oesophagus (up to $7.0 \mathrm{~mm}$ ) in females is almost twice that seen in C. pardalis sp. n. (498 $\mu \mathrm{m}$ and $3.5 \mathrm{~mm}$, respectively). According to Clark (1981), C. heydoni has large lateral alae, a character that is absent in the latter species.

Cylicospirura barusi differs from the new species by the position of the vulva at the level of the intestine (Table 2), and the possession of four cephalic and four external labial papillae. Both $C$. barusi and C. petrowi differ from $C$. pardalis by having females with a shorter and narrower buccal capsule (Table 2).

Despite the low number of specimens at our disposal, the available diagnostic criteria, especially the configuration of the large teeth and the distinct claw-like appearance of the cusps, carry sufficient weight to unequivocally differentiate the current specimens from all remaining species of Cylicospirura.

\section{DISCUSSION}

The taxonomy of the genera presently included in the subfamily Spirocercinae (Spirocercidae) has been developed mainly on the complexity of their cephalic morphology (Chitwood and Wehr 1934, Chabaud 1959a,b, 1975, Yamaguti 1961). Based on the presence of six teeth in the buccal cavity, Chabaud (1959a) recognized Gastronodus, Skrjabinocercina and Petrowospirura as synonyms of Cylicospirura. This concept was not accepted by Skrjabin et al. (1967), who considered the differences in the position of the vulva in females and the number of caudal papillae in males as significant. In a subsequent publication, Chabaud (1975) treated Gastronodus and Skrjabinocercina as subgenera of Cylicospirura while still recognizing Petrowospirura as a synonym of the nominotypical subgenus Cylicospirura. The morphology of the majority of species of Cylicospirura, Gastronodus, Petrowospirura or Skrjabinocercina assigned to Cylicospirura sensu lato is known from their brief original descriptions only. Nevertheless, the available morphological data justify the validation of the genera Gastronodus and Skrjabinocercina.

Cylicospirura is characterized by males that possess six pairs of pedunculate caudal papillae (four precloacal and two postcloacal) and four pairs of sessile papillae situated near the tail tip; the vulva of females is situated close to the oesophago-intestinal junction or near mid-body (Baylis 1927, Kozlov et al. 1964, Mawson 1968, Pence et al. 1978, Arya 1979, Clark 1981, Waid and Pence 1988; present study).

Gastronodus differs from Cylicospirura by having males with nine to ten pairs of pedunculate caudal papillae (six to seven precloacal and three postcloacal) and three pairs of sessile papillae near the tail tip, one large and two smaller; the vulva of females is situated near the anterior end (Singh 1934, 1948).

In contrast, Skrjabinocercina differs by males possessing six pairs of pedunculate caudal papillae (four precloacal and two postcloacal), one pair of sessile precloacal papillae and another one near the tail tip; the vulva is situated near the anus (Matschulsky 1952).

For these three genera we propose the following amended generic diagnoses:

\section{Cylicospirura Vevers, 1922}

Diagnosis. Head papillae represented by four submedian cephalic papillae; in addition, four external labial papillae and (or) six internal labial papillae may be present. No pseudolabia. Buccal capsule short, heavily sclerotized. Six large teeth (two lateral and four submedian) arise in posterior half of buccal capsule, projecting anteriorly, with rounded or pointed tips or bearing cusps. In addition, groups of small accessory teeth may arise from buccal capsule wall. Oesophagus divided into short muscular and long glandular part. Deirids small, spine-like, situated near nerve ring. Male with narrow caudal alae, bearing six pairs of pedunculate caudal papillae (four precloacal and two postcloacal). Four pairs of sessile papillae situated near tail extremity. Single median sessile precloacal papilla usually present. Spicules unequal and dissimilar. Gubernaculum present. Female with short tail; vulva situated near oesophago-intestinal junction or equatorial. Eggs oval, thick-shelled, containing first-stage larva. Parasitic in the alimentary tract of carnivorous mammals. Type species C. subaequalis (Molin, 1860).

\section{Gastronodus Singh, 1934}

Diagnosis. Anterior end with four submedian cephalic papillae. No pseudolabia. Buccal capsule short, heavily sclerotized, armed with two lateral and four submedian teeth. Oesophagus divided into short muscular and long glandular part. Deirids small, spine-like, situated near nerve ring. Male with narrow caudal alae, bearing nine 
to ten pairs of pedunculate caudal papillae (six to seven precloacal and three postcloacal). Three pairs of sessile papillae situated near tail extremity. Single median sessile precloacal papilla present. Spicules unequal and dissimilar. Gubernaculum present. Female with short tail; vulva at level of anterior part of glandular oesophagus. Eggs thick-shelled, containing first-stage larva. Type- and only species Gastronodus strasseni Singh, 1934, parasite of Suncus murinus (Linnaeus) (syn. Crocidura caerulea Kerr) (Soricomorpha: Soricidae) (type-host) in India (type-locality) (Singh 1934, 1948) and from S. murinus in Thailand (Smith and Little 1973).

\section{Skrjabinocercina Matschulsky, 1952}

Diagnosis. Anterior end with four submedian cephalic papillae. Buccal capsule short, heavily sclerotized. Four submedian and two lateral large teeth arise in posterior half of buccal capsule, projecting anteriorly. Oesophagus divided into short muscular and long glandular part. Male with narrow caudal alae, bearing six pairs of pedunculate caudal papillae (four precloacal and two postcloacal). One pair of sessile papillae situated near tail extremity. Spicules unequal and dissimilar. Gubernaculum present. Female with short tail; vulva posterior, situated near anus. Eggs oval, containing first-stage larva. Type- and only species Skrjabinocercina petrowi Matschulsky, 1952 from Allactaga sibirica (Forster) [syn. Allactaga saltator mongolica (Radde)] (Rodentia: Dipodidae) (type-host) in Buryatia, East Siberia, Russia (Matschulsky 1952).

Based on the amended definition of Gastronodus suggested above, a few remarks concerning specimens assigned to this genus following the papers of Singh (1934, 1948) are warranted. Gupta (1960) described G. strasse$n i$ from S. murinus (syn. C. caerulea) in East Pakistan. However, his description differs from the specimens illustrated by Singh $(1934,1948)$, which have teeth of equal length. According to Gupta's (1960; Fig. 19 in his paper) description, the lateral teeth are distinctly larger than the submedian ones. Together with the smaller spicular ratio ( $1: 3.5$ vs $1: 6$ ), one may doubt that they are conspecific with the specimens described by Singh $(1934,1948)$.

Another species, Gastronodus muelleri Gupta et Trivedi, 1985 (originally spelled as Castronodus [sic!] muelleri), was also described from S. murinus (syn. C. caerulea) in India (Gupta and Trivedi 1985). The morphology of this species differs significantly from the original description of $G$. strasseni by males possessing twelve pairs of pedunculate caudal papillae (five precloacal, one adcloacal and six postcloacal), situated on the broad caudal alae, and by females having a narrow conical tail and laying thin-shelled eggs without developed first-stage larvae, which does not correspond to the generic diagnosis of Gastronodus. Therefore, we consider this species as a species incertae sedis.

The genus Petrowospirura was erected as monotypic for P. lyncis, a parasite of Lynx lynx (Linnaeus) and $\mathrm{Fe}$ - lis manul Pallas (Felidae) in Russia (Matschulsky 1952). Based on existing information, Chabaud (1959b) synonymized $P$. lyncis with $C$. subaequalis. Throughout the years, the brief original description of $C$. subaequalis has been amended by Vevers (1922), Yamaguti (1961) and Waid and Pence (1988). As a result of these studies, P. lyncis, as described by Matschulsky (1952), can be distinguished from $C$. subaequalis by having teeth with indistinct cusps that seem variable in number, as opposed to teeth with two well-developed cusps, a longer muscular and glandular oesophagus in males, and a more posteriorly situated vulva in females (Tables 1,2 ).

The particular morphology of its teeth also distinguishes $P$. lyncis from $C$. felineus, which possesses teeth with three well-developed, symmetrical cusps (Pence et al. 1978). In addition, it differs from C. felineus by the more posteriorly situated vulva (Table 2 ). The teeth of $P$. lyncis are equally distinct from those of the remaining two species described prior to it, C. heydoni and C. arctica, both terminating in a pointed tip (Petrow 1927, Mawson 1968). In addition, these species can be readily differentiated by differences in size, spicule length and the position of the vulva (Tables 1,2 ). We, therefore, consider P. lyncis as valid. Based on the presence of six large teeth, four cephalic papillae on the level of the amphids, four pairs of precloacal and two pairs of postcloacal pedunculate papillae, short tail and anterior position of vulva in the female, we propose for it the name Cylicospirura lyncis (Matschulsky, 1952) Junker et Mutafchiev comb. n.

When Chabaud (1959b) synonymized P. lyncis with C. subaequalis, he did not comment on a second species that had by then been assigned to this genus, Petrowospirura petrowi Sadykhov, 1957 from Felis chaus Schreber (Felidae) in Azerbaijan. The morphology of the latter species as described by Sadykhov (1957) corresponds to the generic diagnosis of Cylicospirura. It can be differentiated from all other species in the genus by a combination of characters, including buccal capsule length and width, spicule length and distance of vulva from the anterior end (Tables 1, 2). We therefore propose the new combination Cylicospirura petrowi (Sadykhov, 1957) Junker et Mutafchiev comb. n.

A third species, Petrowospirura barusi Arya, 1979, was described from the stomach of a domestic cat in India (Arya 1979). While Arya (1979) describes P. barusi as having a mouth with two lobes, each with three lips, his illustration of the apical view does not clearly differentiate two lobes but shows the presence of six teeth. Whereas only six teeth are illustrated in apical view, the author reports the presence of twelve longitudinal ridges extending throughout the length of the heavily sclerotized, funnel-shaped buccal capsule and illustrates twelve sharply pointed teeth in the anterior extremity of a female (Arya 1979 - Fig. 1a in his paper). This could suggest the presence of posteriorly situated accessory teeth between 
the six main teeth, similar to the arrangement of groups of smaller teeth between the six large teeth of $C$. crocutae.

Males are described as possessing four pairs of precloacal and two pairs of postcloacal pedunculate papillae (sessile papillae were not described), and the position of the vulva in females to be pre-equatorial (Arya 1979). Based on the morphological characteristics of P. barusi outlined above, we suggest that this species has to be assigned to Cylicospirura as Cylicospirura barusi (Arya, 1979) Junker et Mutafchiev comb. n. The description of the cephalic morphology of $C$. barusi was too perfunctory to differentiate it with certainty from C. subaequalis, C. felineus or C. skrjabini, which share similar morphometrics (Tables 1,2), and future studies might demonstrate its synonymy with one of these.

On the basis of the above comparisons, we can conclude that the following species correspond to the generic diagnosis of Cylicospirura:

(1) Cylicospirura subaequalis (Molin, 1860) Vevers, 1922 (type species) from Puma concolor and Puma yagouaroundi (type host not designated) in Brazil (type locality) (Molin 1860) and USA (Waid and Pence 1988, Rickard and Foreyt 1992, Ferguson et al. 2011); Panthera tigris (Linnaeus) (Felidae), died in London, originated from Malay Peninsula (Vevers 1922), Madras, India (Mudaliar and Alwar 1947); domestic cat, Felis catus (Linnaeus), Felis chaus (Felidae) and Vulpes vulpes Linnaeus (Canidae) in India (Yamaguti 1961, Rahman et al. 1971, Pillai et al. 1981). The records of C. subaequalis from Lynx canadensis (Kerr) in Canada (van Zyll de Jong 1966, Threlfall 1969) and Alaska (Neiland 1966) and from Lynx rufus (Schreber) in USA (Little et al. 1971) were considered as dubious in subsequent studies (Pence et al. 1978, Waid and Pence 1988, Ferguson et al. 2011). In view of the results of the present study, the species identifications of previous records of C. subaequalis from Crocuta crocuta in Ethiopia (Graber et al. 1980) and Kenya (Round 1968), from Panthera leo in Rutshuru, Democratic Republic of the Congo (Sandground 1929), Central African Republic (Graber and Thal 1980) and from Panthera pardus in Sierra Leone (Sandground 1930), which were not accompanied by descriptions, seem to require further studies.

(2) Cylicospirura advena Clark, 1981 from Felis catus in New Zealand (Clark 1981).

(3) Cylicospirura arctica (Petrow, 1927) Chabaud, 1959 from Vulpes lagopus Linnaeus and Canis lupus familiaris Linnaeus in Arkhangelskaya Oblast', Russia (Petrow 1927). A type host was not mentioned in the original description and type specimens were registered as syntypes (Chertkova et al. 1984). Therefore, no type host can be designated.

(4) Cylicospirura barusi (Arya, 1979) Junker et Mutafchiev comb. n. from Felis catus (syn. Felis domestica) in India (Arya 1979).
(5) Cylicospirura crocutae sp. n. from Crocuta crocuta in Zimbabwe (present study).

(6) Cylicospirura felineus (Chandler, 1925) Sandground, 1933 from Felis catus (type host) in India (type locality) (Chandler 1925), Tasmania (Gregory and Munday 1976), Australia (Pavlov and Howell 1977) and South Africa (Junker et al. 2006); Lynx canadensis in USA (Pence et al. 1978); Lynx rufus in USA (Pence et al. 1978, Watson et al. 1981, Tiekotter 1985, Ferguson et al. 2011); Felis silvestris ocreata Gmelin (syn. Felis ocreata Gmelin) and Vulpes vulpes in Algeria (Seurat 1913, 1915, 1917; for the identifications see Sandground 1933 and Yamaguti 1961; Figs. 1, 2 of Seurat 1913,); Panthera tigris tigris Pocock (Felidae) in Indochina (Yamaguti 1961); Prionailurus bengalensis (Kerr) (Felidae) in Vietnam (Sandground 1933); Vulpes lagopus Linnaeus and V. vulpes in Alaska (Rausch et al. 1990).

(7) Cylicospirura heydoni (Baylis, 1927) Chabaud, 1959 from Dasyurus sp. (Dasyuridae) in Australia (type locality) (Baylis 1927); based on the locality, Cairns, Queensland, the host was likely Dasyurus hallucatus Gould or Dasyurus maculatus (Kerr); D. maculatus in New South Wales, Australia (Mawson 1968); Dasyurus viverrinus Shaw (syn. Dasyurus quoll Zimmermann) in Tasmania (Mawson 1968); D. hallucatus in Northern Territory, Australia (Oakwood and Spratt 2000); Dasyurus albopunctatus Schlegel in New Guinea (Ladds et al. 2006); Thylogale billardierii (Desmarest) (Macropodidae) in Tasmania (Ladds et al. 2006); Felis catus in Tasmania (Milstein and Goldsmid 1997).

(8) Cylicospirura lyncis (Matschulsky, 1952) Junker et Mutafchiev comb. n. from Lynx lynx and Felis manul in Buryatia, East Siberia, Russia (Matschulsky 1952). The original spelling of the species name was 'lynxi' (see Matschulsky 1952), but was later emended to 'lyncis' by Chertkova et al. (1984). A type host was not mentioned in the original description and type specimens were registered as syntypes (Chertkova et al. 1984). Therefore, no type host can be designated.

(9) Cylicospirura pardalis sp. n. from Panthera pardus in South Africa (present study).

(10) Cylicospirura petrowi (Sadykhov, 1957) Junker et Mutafchiev comb. n. from Felis chaus (type host) in Azerbaijan (type locality) (Sadykhov 1957); Felis silvestris Schreber in Bulgaria (Jančev and Genov 1978) and Germany (Krone et al. 2008).

(11) Cylicospirura skrjabini Kozlov, Owsjukova et Radkewitch, 1964 from Vulpes lagopus near the mouth of the $\mathrm{Ob}$ River and in Chukotka Peninsula, Russia and Vulpes vulpes in Chukotka Peninsula (Kozlov et al. 1964). A type host was not mentioned in the original description and type specimens were registered as syntypes (Chertkova et al. 1984). Therefore, no type host can be designated.

Representatives of Cylicospirura parasitize a wide range of carnivorous mammals comprising Canidae, 
Dasyuridae, Felidae and Hyaenidae. Especially C. felineus and $C$. subaequalis have been recorded as parasite of various hosts from all major terrestrial ecozones (see above). However, in some instances, subsequent detailed morphological studies revealed part of these records as erroneous (Sandground 1933, Yamaguti 1961, Pence et al. 1978, Waid and Pence 1988). The description of two new species of Cylicospirura from a single $C$. crocuta and a single $P$. pardus, some 70 years after the genus had first been recorded from these hosts, strongly suggests that this parasitic nematode group is likely more diverse than currently known.

Acknowledgments. We thank Dr. Lin-Mari de Klerk-Lorist, State Veterinarian, Skukuza, South Africa, for facilitating logistics regarding the specimens from the leopard. We are especially grateful to Prof. Boyko B. Georgiev, Bulgarian Academy of Sciences and Prof. Joop Boomker, Souh Africa, for their many valuable comments on the draft of the manuscript.

\section{REFERENCES}

Arya S.N. 1979: A new nematode of the genus Petrowospirura (Spiruroidea) from the cat, Felis domestica from India. Folia Parasitol. 26: 293-294.

Bauer H., Nowell K., Packer C. 2008: Panthera leo. In: International Union for Conservation of Nature 2012. IUCN Red List of Threatened Species (version 2012.1.), www.iucnredlist.org, 09/2012.

BAylis H.A. 1927: Some new parasitic nematodes from Australia. Ann. Mag. Nat. Hist., Ser. 9, 20: 214-225.

Chabaud A.G. 1959a: Phénomène d'évolution régressive des structures céphaliques et classification des nématodes Spiruroidea. Parassitologia 1: 11-20.

Chabaud A.G. 1959b: Sur la systématique des nematodes proches de Spirocerca lupi (Rud., 1809). Parassitologia 1: 129-135.

Chabaud A.G. 1975: Keys to genera of the order Spirurida. Part 2. Spiruroidea, Habronematoidea and Acuarioidea. In: R.C. Anderson, A.G. Chabaud and S. Willmott (Eds.), CIH Keys to the Nematode Parasites of Vertebrates. Archival volume 2009. CABI Publishing, Oxfordshire, pp. 361-390.

Chabaud A.G., Petter A.J. 1961: Remarques sur l'évolution des papilles cloacales chez les nématodes phasmidiens parasites de vertébrés. Parassitologia 3: 51-70.

Chander A.C. 1925: The helminthic parasites of cats in Calcutta and the relation of cats to human helminthic infections. Ind. J. Med. Res. 13: 213-228 + Plts. 5, 6.

Chertkova A.N., Kosupko G.A., Khrustalev A.V. 1984: [Catalogue of Type Specimens of Species of Helminths from the Collection of the Central Helminthological Museum]. Publishing House VIGIS, Moscow, 92 pp. (In Russian.)

Chitwood B.G., Wehr E.E. 1934: The value of cephalic structures as characters in nematode classification, with special reference to the superfamily Spiruroidea. Z. Parasitenkd. 7: 274-335.

Clark W.C. 1981: Cylicospirura advena n. sp. (Nematoda: Spirocercidae) a stomach parasite from a cat in New Zealand, with observations on related species. Syst. Parasitol. 3: 185-191.

Ferguson J.A., Woodberry K., Gillin C.M., Jackson D.H., Sanders J.L., Madigan W., Bildfell R.J., Kent M.L. 2011: Cylicospirura species (Nematoda: Spirocercidae) and stomach nodules in cougars (Puma concolor) and bobcats (Lynx rufus) in Oregon. J. Wildl. Dis. 47: 140-153.

Graber M., Blanc P., Delavenay R. 1980: Helminthes des animaux sauvages d'Ethiopie. I. Mammifères. Rev. Elev. Méd. Vét. Pays Trop. 33: 143-158.

Graber M., Thal J. 1980: L'échinococcose des artiodactyles sauvages de la République Centrafricaine: existence probable d'un cycle lion-phacochère. Rev. Elev. Méd. Vét. Pay. Trop. 33: 51-59.

Gregory G.G., Munday B.L. 1976: Internal parasites of feral cats from the Tasmanian Midlands and King Island. Aust. Vet. J. 52: $317-320$.
Gupta S.P. 1960: Nematode parasites of vertebrates of East Pakistan. V. Spirurid nematodes. Can. J. Zool. 38: 575-584.

Gupta S.P., Trivedi K.K. 1985: Nematode parasites of vertebrates. On two new nematodes from mammals of India. Ind. J. Helminthol. 37: 18-25.

Henschel P., Hunter L., Breitenmoser U., Purchase N., Pakker C., Khorozyan I., Bauer H., Marker L., Sogbohossou E., Breitenmoser-Wursten C. 2008: Panthera pardus. In: International Union for Conservation of Nature 2012. IUCN Red List of Threatened Species. (version 2012.1.) www.iucnredlist. org, 09/2012.

Honer O., Holekamp K.E., Mills G. 2008: Crocuta crocuta. In: International Union for Conservation of Nature 2012. IUCN Red List of Threatened Species. (Version 2012.1.), www.iucnredlist.org, 09/2012.

JANČEV J., GENOV T. 1978: [Helminthofauna of the wild cat (Felis silvestris Schreb.) in Bulgaria.] Khelmintologiya 6: 81-101. (In Bulgarian.)

Junker K., Vorster J.H., Boomker J. 2006: First record of Cylicospirura (Cylicospirura) felineus (Chandler, 1925) Sandground, 1933 (Nematoda: Spirocercidae) from a domestic cat in South Africa. Onderstepoort J. Vet. Res. 73: 257-262.

Kozlov D.P., Owsunkova N.I., Radkewitch Z.P. 1964: [Cylicospirura skrjabini n. sp. (Spirurata) from foxes.] Trudy GELAN 14: 105-108. (In Russian.)

Krone O., Guminsky O., Meinig H., Herrmann M, Trinzen M., Wibielt G. 2008: Endoparasite spectrum of wild cats (Felis silvestris Schreber, 1777) and domestic cats (Felis catus L.) from the Eifel, Pfalz region and Saarland, Germany. Eur. J. Wildl. Res. 54: 95-100.

Ladds P.W., Sammons J., Beveridge I. 2006: Enteritis caused by Cylicospirura heydoni infection in two Tasmanian pademelons (Thylogale billardierii). Aust. Vet. J. 84: 412-413.

Little J.W., Smith J.P., Knowlton F.F., Bell R.R. 1971: Incidence and geographic distribution of some nematodes in Texas bobcats. Texas J. Sci. 22: 302-314.

Matschulsky S.N. 1952: [Two new genera and species of spirurids of mammals]. Trudy GELAN 6: 315-322. (In Russian.)

Mawson P.M. 1968: Two species of Nematoda (Spirurida: Spiruridae) from Australian dasyurids. Parasitology 58: 75-78.

Milstein T.C., Goldsmid J.M. 1997: Parasites of feral cats from southern Tasmania and their potential significance. Aust. Vet. J. 75: 218-219.

Molin R. 1860: Una monografia del genre Spiroptera. Sitzungsber. Akad. Wiss. Wien Math. Naturwiss. K1. 37: 911-1005.

Mudaliar S.V., Alwar V.S. 1947: A check-list of parasites (Class-Nematoda) in the Department of Parasitology, Madras Veterinary College Laboratory. Ind. Vet. J. 24: 77-94.

Neiland K.A. 1966: Disease, parasite and data collections. Vol. 7. Annual Project Segment Report, Federal Aid in Wildlife Res- 
toration Projects W-6-R-5, July 1966. (Cited after Pence et al. 1978.)

OAKwood M., Spratt D.M. 2000: Parasites of the northern quoll, Dasyurus hallucatus (Marsupialia: Dasyuridae) in tropical savanna, Northern Territory. Aust. J. Zool. 48: 49-90.

Pavlov P.M., Howell M.J. 1977: Helminth parasites of Canberra cats. Aust. Vet. J. 53: 599-600.

Pence D.P., Samoil H.P., Stone J.E. 1978: Spirocercid stomach worms (Nematoda: Spirocercidae) from wild felids in North America. Can. J. Zool. 56: 1032-1042.

Petrow A.M. 1927: Spirocerca arctica - a new nematode parasite of Canis familiaris and Vulpes lagopus in North Russia. Ann. Trop. Med. Parasitol. 21: 261-266.

Pillai K.M., Pythal C., Sundaram R.K. 1981: A note on the occurrence of Cylicospirura subaequalis (Molin, 1860) (Spiruridae: Nematoda) in a jungle kitten (Felis chaus) in Kerala. Kerala J. Vet. Sci. 12: 155-156.

Rahman S.A., Hegde K.S., Mohiyudeen S., Seshadri S.J., Rahamatulla P.M., Rajasekharan D. 1971: Study of Cylicospirura subaequalis (Molin, 1860) and the histopathology of the nodule in the stomach of a cat. Ind. Vet. J. 48: 683-687.

Rausch R.L., Fay F.H., Williamson F.S.L. 1990: The ecology of Echinococcus multilocularis (Cestoda: Taeniidae) on St. Lawrence Island, Alaska. II. Helminth populations in the definitive host. Ann. Parasitol. Hum. Comp. 65: 131-140.

Rickard L.G., Foreyt W.J. 1992: Gastrointestinal parasites of cougars (Felis concolor) in Washington, and the first report of Ollulanus tricuspis in a sylvatic felid from North America. J. Wildl. Dis. 28: 130-133.

Round M.C. 1968: Check list of the helminth parasites of African mammals of the orders Carnivora, Tubulidentata, Proboscidea, Hyracoidea, Artiodactyla and Perissodactyla. Technical Communication of the Commonwealth Bureau of Helminthology, St. Albans, 38, $252 \mathrm{pp}$.

SADYKhov I.A. 1957: [A new species of nematode, Petrowospirura petrowi n. sp. from the intestine of Felis chaus in Azerbaijan]. Doklady Akademii Nauk Azerbaidzhanskoi SSR 13: 901-904. (In Russian.)

SANDGRound J.H. 1929: A new liver fluke from a monkey and new parasitic roundworms from various African animals. Proc. U.S. Nat. Mus. 75: 1-11.

SANDGRound J.H. 1930: Report of the Harvard-African Expedition upon the African Republic of Liberia and the Belgian Congo. Pt. III. Medical and Biological Investigations: 28, Notes and descriptions of some parasitic helminths collected by the Expedition. Contrib. Dept. Trop. Med. and Inst. Trop. Biol. and Med. (Harvard Univ.), v. 1, pp. 462-486. (Cited after Round 1968.)

SANDGRound J.H. 1933: Report on the nematode parasites collected by the Kelley-Roosevelts expedition to Indo-China with

Received 19 February 2013 descriptions of several new species. Part 1. Parasites of birds. Part 2. Parasites of mammals. Z. Parasitenkd. 5: 542-583.

Seurat L.G. 1913: Sur deux Spiroptères du chat ganté (Felis ocreata Gmel.). C. R. Séanc. Soc. Biol. 74: 676-679.

Seurat L.G. 1915: Sur deux nouveaux parasites du renard d'Algérie. C. R. Séanc. Soc. Biol. 78: 122-126.

Seurat L.G. 1917: Sur les Spiroptères des carnivores du NordAfricain. Bull. Soc. Hist. Nat. Afr. Nord. 8: 21-24.

SingH S.N. 1934: Castronodus [sic!] strasseni, g. et sp. n. A new nematode parasite of Crocidura coerula - the common muskshrew or as it is usually called musk-rat (vernacular: chachundar). Curr. Sci. 2: 287.

SinGH S.N. 1948: Gastronodus strasseni Singh, 1934, and its affinities with Spirocerca lupi (Rudolphi, 1809) Chitwood, 1933. J. Helminthol. 22: 219-225.

Skrjabin K.I., Sobolev A.A., Ivashrin V.M. 1967: [Spirurata of animals and man and the diseases caused by them. Part 5 . Supplement]. In: K.I. Skrjabin (Ed.), Osnovy Nematodologii, Vol. 19. Publ. House Nauka, Moscow, 239 pp. (In Russian.)

Smith P.C., Little M.D. 1973: Cylicospirura strasseni in the Asian house shrew (Suncus murinus) in Thailand. J. Parasitol. 59: 793-796.

Threlfall W. 1969: Further records of helminths from Newfoundland mammals. Can. J. Zool. 47: 197-201.

Tiéotter K.L. 1985: Helminth species diversity and biology in the bobcat, Lynx rufus (Schreber), from Nebraska. J. Parasitol. 71: $227-234$

Vevers G.M. 1922: On the parasitic Nematoda collected from mammalian hosts which died in the Gardens of the Zoological Society of London during the years 1919-1921; with a description of three new genera and three new species. Proc. Zool. Soc. London. 61: 901-919.

Waid D.D., Pence D.B. 1988: Helminths of mountain lions (Felis concolor) from southwestern Texas, with a redescription of Cylicospirura subaequalis (Molin, 1860) Vevers, 1922. Can. J. Zool. 66: 2110-2117.

Watson T.G., Nettles V.F., Davidson W.R. 1981: Endoparasites and selected infectious agents in bobcats (Felis rufus) from West Virginia and Georgia. J. Wild1. Dis. 17: 547-554.

Wilson D.E., Reeder D.A. (Eds.) 2005: Mammal Species of the World. A Taxonomic and Geographic Reference. Third edition. Johns Hopkins University Press, Baltimore, Maryland, $2142 \mathrm{pp}$.

Yamaguti S. 1961: The Nematodes of Vertebrates. Systema Helminthum. Volume III, Parts I and II. Interscience Publishers, New York, $1261 \mathrm{pp}$.

van Zyll de Jong C.G. 1966: Parasites of the Canada lynx, Felis (Lynx) canadensis (Kerr). Can. J. Zool. 44: 499-509. 